\title{
Endovascular interventions in the management of acute extremity trauma: a narrative review
}

\author{
Aditya Khurana ${ }^{1}$, Keith Quencer ${ }^{3}$, Aman Saini $^{2}$, Andrew Sill ${ }^{2}$, Hassan Albadawi ${ }^{2}$, Leila Jamal $^{2}$, \\ Sailendra Naidu ${ }^{2}$, Indravadan Patel $^{2}$, Sadeer Alzubaidi ${ }^{2}$, Rahmi Oklu ${ }^{2}$ \\ ${ }^{1}$ Mayo Clinic Alix School of Medicine, Mayo Clinic, Scottsdale, AZ, USA; ${ }^{2}$ Division of Vascular and Interventional Radiology, Minimally Invasive \\ Therapeutics Laboratory, Mayo Clinic, Scottsdale, AZ, USA; ${ }^{3}$ University of Utah, Interventional Radiology, Salt Lake City, Utah, USA \\ Contributions: (I) Conception and design: A Khurana, R Oklu; (II) Administrative support: R Oklu; (III) Provision of study materials or patients: R \\ Oklu; (IV) Collection and assembly of data: A Khurana, R Oklu, K Quencer; (V) Data analysis and interpretation: A Khurana, R Oklu, K Quencer; (VI) \\ Manuscript writing: All authors; (VII) Final approval of manuscript: All authors. \\ Correspondence to: Rahmi Oklu, MD, PhD. 13208 E Shea Blvd, Scottsdale, AZ 85259 Email: Oklu.Rahmi@mayo.edu.
}

\begin{abstract}
Minimally invasive endovascular interventions including stenting and embolization have been widely adopted for the treatment of emergent and traumatic thoracoabdominal injuries. In recent years, these techniques have been utilized in the setting of extremity vascular trauma with promising outcomes. By allowing for the rapid diagnosis and subsequent treatment of penetrating or blunt vascular extremity trauma, these techniques can help to minimize blood loss, reduce operative complications, and potentially prevent limb amputation. Here, we present a narrative review of the ever-increasing role of minimally invasive interventions in the management of extremity trauma and compare its use and outcomes to open surgical repair. A special focus is placed on diagnostic imaging modalities in trauma and the role of interventional radiologists in the work-up and treatment of extremity trauma. We discuss diagnostic imaging modalities that aid in the triaging of extremity trauma, such as Doppler sonography, CT angiography, and catheterbased angiography. We present an overview on the literature related to endovascular interventions such as embolotherapy and stent grafting as well as the technical challenges associated with each technique. Finally, we present our own cases on the workup and endovascular treatment of extremity trauma, including CT angiography, particulate and coil embolization, and stent graft placement.
\end{abstract}

Keywords: Trauma; interventional radiology (IR); endovascular interventions; extremity trauma

Submitted Nov 05, 2020. Accepted for publication Jun 16, 2021.

doi: $10.21037 /$ atm-20-5428

View this article at: https://dx.doi.org/10.21037/atm-20-5428

\section{Introduction}

Trauma is the largest cause of mortality in those under 45 and the third overall cause of mortality regardless of age (1). Vascular trauma is associated with a high mortality rate; while vascular injuries make up 1-2\% of all trauma cases but contribute to upwards of $20 \%$ of all trauma-related mortality $(2,3)$. Approximately $75-80 \%$ of extremity trauma is penetrating and carry with them a high likelihood of vascular involvement (4). Blunt trauma injuries with vascular involvement include supracondylar fractures, posterior knee dislocation, and tibial plateau fractures.
In recent years, endovascular approaches in the management of upper and lower vascular trauma have been increasingly utilized due to advances in technology and procedural techniques (5). Endovascular interventions can have both diagnostic (catheter-based angiography to detect extravasation) and therapeutic (urgent embolization or stenting to maintain the integrity of the injured vasculature) utility. These endovascular techniques can even allow for simultaneous diagnosis and intervention in peripheral vascular trauma and are especially useful in cases where sites of bleeding are difficult to access or identify. In the case of extremity trauma, endovascular interventions can 
achieve minimally invasive hemostasis whether it be by embolization or stent graft placement (6).

According to recent Society for Interventional Radiology guidelines for the role interventional radiology (IR) in acute trauma care, endovascular techniques can be used when open surgery increases risk of injury to surrounding structures, or when blood loss needs to be rapidly minimized (7).

We review the diagnosis and initial work-up of extremity trauma as well as various endovascular approaches. Technical challenges associated with the utilization of minimally invasive interventions in extremity trauma are also discussed. We present the following article in accordance with the NARRATIVE REVIEW reporting checklist. Literature review was conducted by compiling previous case reports, retrospective studies, and guideline commentaries that were indexed on the PubMed database.

We present the following article in accordance with the Narrative Review reporting checklist (available at https:// dx.doi.org/10.21037/atm-20-5428).

\section{Assessment of extremity trauma}

Assessment and initial stabilization of extremity trauma is incorporated in the primary survey. Focused physical exam of the extremity is performed to determine the location and extent of injury. Clear signs of vascular extremity injury include active bleeding, expanding pulsatile hematoma, ongoing external blood loss, bruit/thrill heard over the wound, absent distal pulses with or without distal ischemic changes (8). If entry or exit wound is clearly present, the expected path of injury should be sought to evaluate likelihood of major arterial injury (9). Traditionally, patients with significant hemodynamic instability secondary to blood loss from extremity trauma are best served with emergent surgical repair and possible amputation. Amputation would be determined by the operating surgeon based on a number of factors, including tissue damage, ischemia, shock, and age of the patient; an objective and validated measure is the Mangled Extremity Severity Score (10). However, depending on institutional practice and operator preference, endovascular intervention in a hybrid operating room can be considered in unstable patients.

\section{Diagnostic imaging}

There are a variety of diagnostic modalities that can be used in the setting of vascular extremity trauma including
Doppler sonography, computed tomographic angiography (CTA) and digital subtraction angiography. Doppler sonography is a low cost and readily available tool to screen for vascular extremity trauma. As ultrasound is readily available in the trauma bay for a Focused Assessment with Sonography in Trauma (FAST) scan, this can be used to assess for the presence of a hematoma, pseudoaneurysm or vessel occlusion (7). In one systematic review, ultrasound was shown to have a sensitivity of $84.6 \%$ and a specificity of $99.1 \%$ in the evaluation of significant vascular extremity trauma $(5,11)$.

CT angiography is rapid, highly sensitive and highly specific for detecting major vascular injury $(12,13)$. In two prospective studies, the sensitivity of CTA in detecting focal arterial injuries in the proximal extremities ranged from $90-100 \%$, while the specificity was greater than $98 \%(14,15)$. An additional meta-analysis by Jens et al. showed a sensitivity of $96.2 \%$ and a specificity of $99.2 \%$ (16). In a study by Wallin et al., if a patient had a normal CTA, surgical or endovascular intervention was rarely needed (17) (Figure 1). CTA can detect below the knee vascular occlusion in cases of fracture (Figure 2) as well as large vessel (popliteal artery) occlusion in the setting of posterior knee dislocation (Figure 3).

While conventional angiography is the gold standard for diagnosing vascular injury it is invasive and less available. A major advantage of catheter-based angiography is the ability to both diagnose and treat $(3,18,19)$. Angiographic findings of life or limb-threatening injury include active contrast extravasation, large pseudoaneurysms, vessel transection or vessel occlusion. Minor findings that are non-limb threatening would include vessel narrowing, occlusion of noncritical branches and small arteriovenous fistulas (9). When angiography was previously the preferred method of diagnosing extremity trauma, the necessity of the procedure would be determined based on positive physical exam findings that indicate a high probability of arterial injury. Those with a negative physical exam could receive angiographies electively (20).

\section{Endovascular techniques in extremity trauma}

Extrapolating from peripheral arterial data, patients undergoing endovascular intervention for extremity trauma may have fewer complications and shorter length-ofhospital-stays than patients undergoing open repair (21). This may be especially true in regions where open surgery would cause iatrogenic complications (5). Endovascular interventions in extremity trauma have been associated 


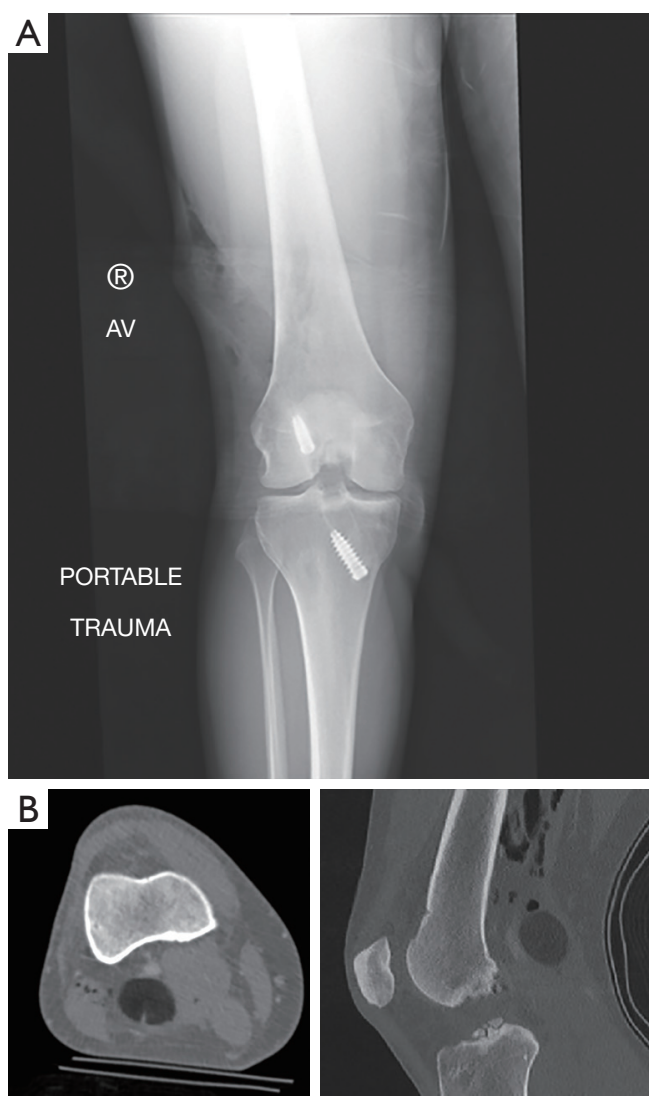

Figure 1 Negative CT Angiography for vascular injury. This 27-year-old female was impaled by a large tree branch during a mountain biking accident. Initial exam and plain radiograph (A) showed the branch which speared behind the knee, raising concern for popliteal injury. Axial and Sagittal images from a computed tomographic angiography (CTA) (B) showed no injury to the popliteal artery. The branch was successfully and uneventfully removed without further intervention.

with decreased blood loss compared to open surgery (22). Endovascular techniques have been used in both upper and lower extremity trauma cases; the majority of data is from case series including reported technical and clinical success in all lower extremity arteries $(19,23,24)$. Iliac artery injuries can be quite severe and are associated with significant mortality rates upwards of $40 \%$ (25), necessitating the need for rapid intervention. Open surgical exposure of the iliac arteries is often difficult and endovascular approach may be preferred. Though endovascular techniques present many benefits to open surgery in regards to patient outcomes, these methods may be limited in cases where the vessel is transected, as this would prevent the catheter from being able to cross the site
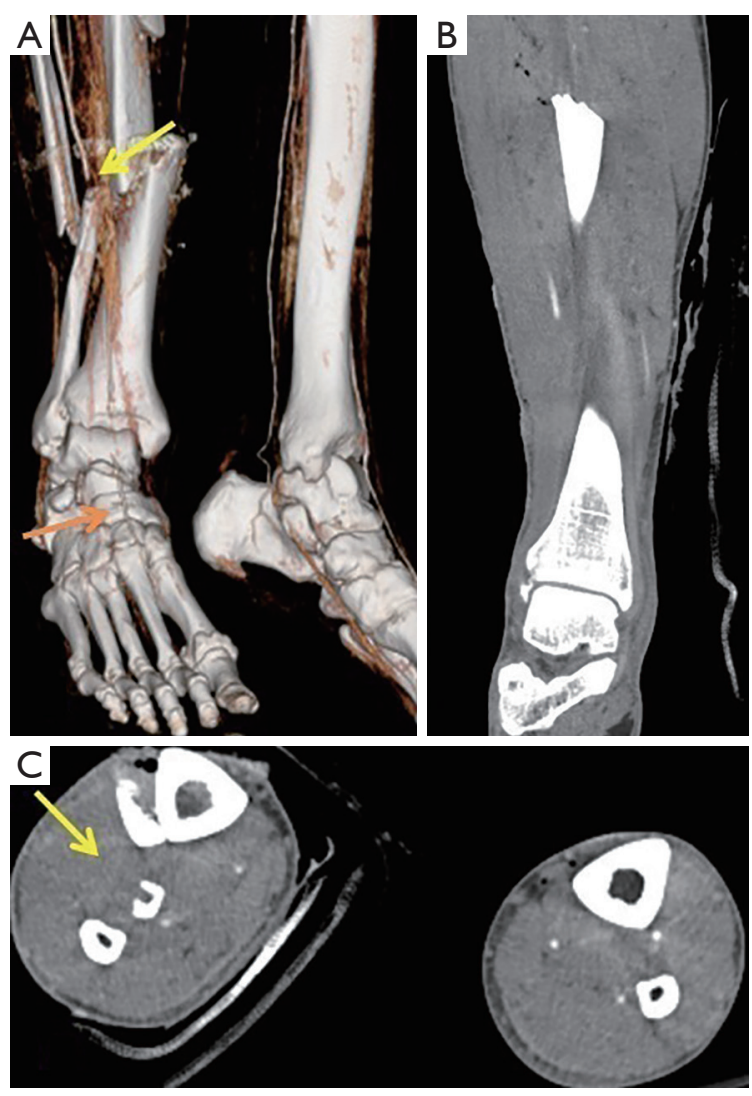

Figure 2 CT angiography to evaluate arterial injury in trauma. (A) 3D volume rendering technique (VRT) demonstrating a complex, open comminuted fracture of the right tibia and fibula. Abrupt occlusion of the anterior tibial artery (yellow arrow) with reconstitution of the dorsal pedis artery (orange arrow) is demonstrated. (B) Coronal multiplanar reconstruction (MPR) shows abrupt occlusion of the artery. (C) Axial images show non opacification of the right anterior tibial artery (yellow arrow) with opacification of the posterior tibial artery and peroneal artery. No evidence of extravasation or pseudoaneurysm. Left leg with normal opacification as a reference.

of injury. There is still a need for more evaluation of the longterm patency rates for certain endovascular interventions like stent grafts (12). At the time of this review, there does not appear to be any previously published prospective series evaluating endovascular versus open approaches.

Upper extremity traumatic injuries experience is more limited but both stent graft placement and coil embolization has been described (26). An endovascular approach is preferred for the axillary-subclavian region due to important adjacent structures in this region such as the brachial plexus and veins 


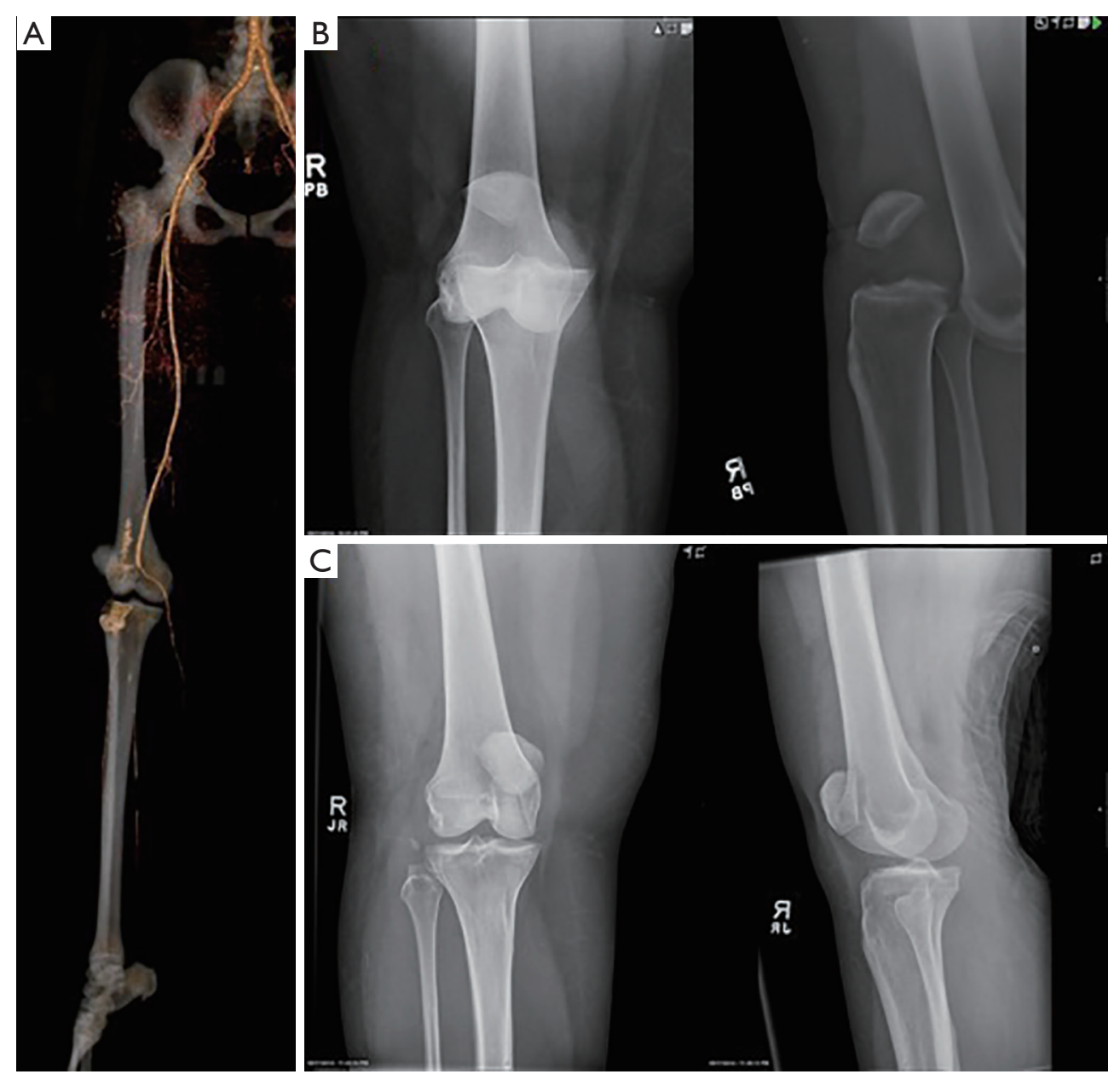

Figure 3 CT angiography to evaluate vascular injury in posterior knee dislocation. Patient presented with posterior right knee dislocation with concern for injury to the popliteal artery. (A) 3D volume rendering technique of computed tomographic angiography (CTA) to assess for injury to the right popliteal artery. CTA ruled out any sort of vascular injury and so reduction was pursued. (B) Anterior-posterior (AP) and lateral views of the posterior dislocation in the right leg. (C) Post-reduction images in the AP and lateral views.

which are at risk for injury with an open surgical approach.

The two general endovascular approaches in peripheral arterial trauma include embolization and stent grafting (27). The site and size of vessel injury, whether it is in a main vessel or distal branch, and the type of injury that is manifesting (i.e., active extravasation or pseudoaneurysm formation) determines whether embolization or stent grafting is used (28). Other lesser used interventions include temporary balloon occlusion, often done as an adjunct to open surgery and percutaneous thrombin injection $(4,29)$.

\section{Embolotberapy}

Embolization is commonly performed for vascular extremity trauma and involves the endovascular deployment of an embolic material to intentionally occlude an artery (Figure 4). It has a high success rate in controlling hemorrhage and offers minimal complications when compared to open surgical approaches. Proximal and distal control to the site of vessel injury should be achieved to prevent rebleeding from collateral or retrograde flow. This method of treatment should not be used if vessel occlusion would cause distal limb ischemia and is better suited for muscular branches (e.g., thigh bleed from bleeding from a branch of the profunda femoris artery) (30). When performing embolization, extra care should be made to avoid non-target embolization.

Once embolotherapy is considered, different embolic agents may be used depending on operator preference, 

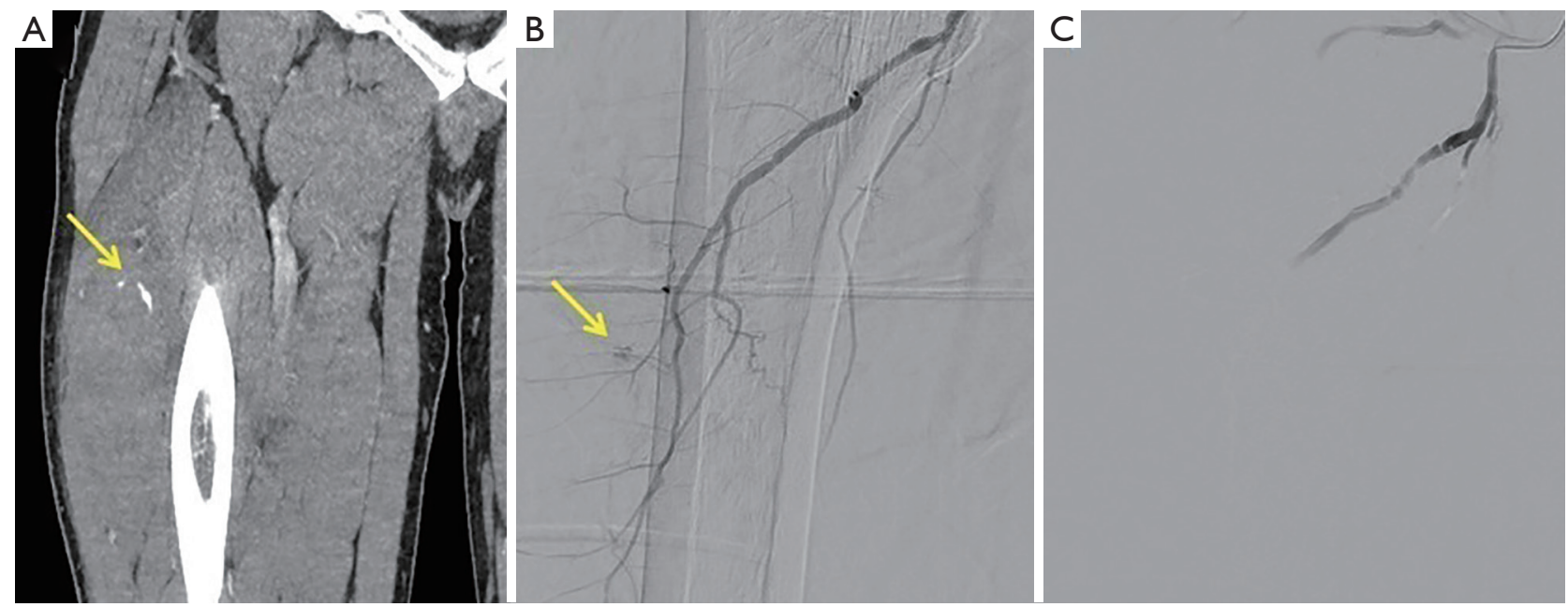

Figure 4 Particulate embolization of active bleeding in the right thigh. A 71-year-old man currently anticoagulated due to atrial fibrillation presents with right thigh swelling after a fall. (A) CT angiogram shows active extravasation (yellow arrow) in the vastus lateralis muscle with surrounding hematoma. (B) Angiogram with microcatheter a branch of the deep femoral artery demonstrates active extravasation correlating with the CT (yellow arrow). (C) Following embolization using 300-500 $\mu \mathrm{m}$ spherical particles, no evidence of bleeding or extravasation is seen.

anatomic complexity, and whether the embolization is desired to be temporary or permanent. Gelfoam is a commonly used temporary embolic agent (31). There are many benefits of Gelfoam including its availability and low cost. Gelfoam will typically recanalize within $2-3$ weeks, allowing ample time to initially stop extravasation and then allow the vessel to naturally heal $(31,32)$. If a more permanent embolic solution is required, coils can be used and are usually effective for medium or small sized arteries (Figures 5,0).

Liquid embolic agents such as glues are used frequently in arteriovenous malformation treatment (33) but have limited use in trauma cases due to risk of accidental distal embolization. They can also be sclerosing, which can damage vessel walls leading to increased risk of tissue ischemia and necrosis (31). Nevertheless, the inflammatory reaction and subsequent instant thrombosis they produce may be desired in certain situations. For example, there are reported case studies of Onyx being used as an embolization agent for traumatic and non-traumatic peripheral vascular lesions (34).

\section{Endovascular stent grafting}

If the site of bleeding or injury involves a major vessel whose occlusion would lead to limb ischemia or other complications, stent grafting would be the endovascular treatment of choice (Figure 7). The location of vascular extremity injuries, whether they are centrally or distally located, influences the technique used. More centrally located injuries (large main vessels) require the use of endovascular stent grafts. Stents have been shown to be efficacious in both upper extremity vessels (subclavian, axillary) and lower extremity vessel bleeds (femoral, popliteal) (12).

Small case series remain the best evidence for their efficacy, safety and long-term patency. One of the largest series to date included 57 patients with subclavian arterial injury treated with stent grafting. No limb loss, need for open surgery or deaths were reported (27). In a cohort of 18 patients treated with endovascular stent placement for peripheral arterial injury, Biagioni et al. demonstrated a $100 \%$ technical success rate as well as a patency rate of $92.3 \%$ and $61.5 \%$ at one and two years follow-up (35). In another study of 28 patients receiving grafting for arterial injury, 6 required a secondary procedure, and the limb salvage rate was $92 \%$ at 45 days and $79 \%$ at 93 days (36). Complications of stent grafting include stent fractures especially at sites of flexion and extension such as the common femoral artery of distal superficial femoral/ popliteal region (Figure 7). From 29 studies analyzed over the course of a 10-year period, the incidence of reported fractures ranged from $0-65 \%$ for stents placed in the femoropopliteal region (37). 

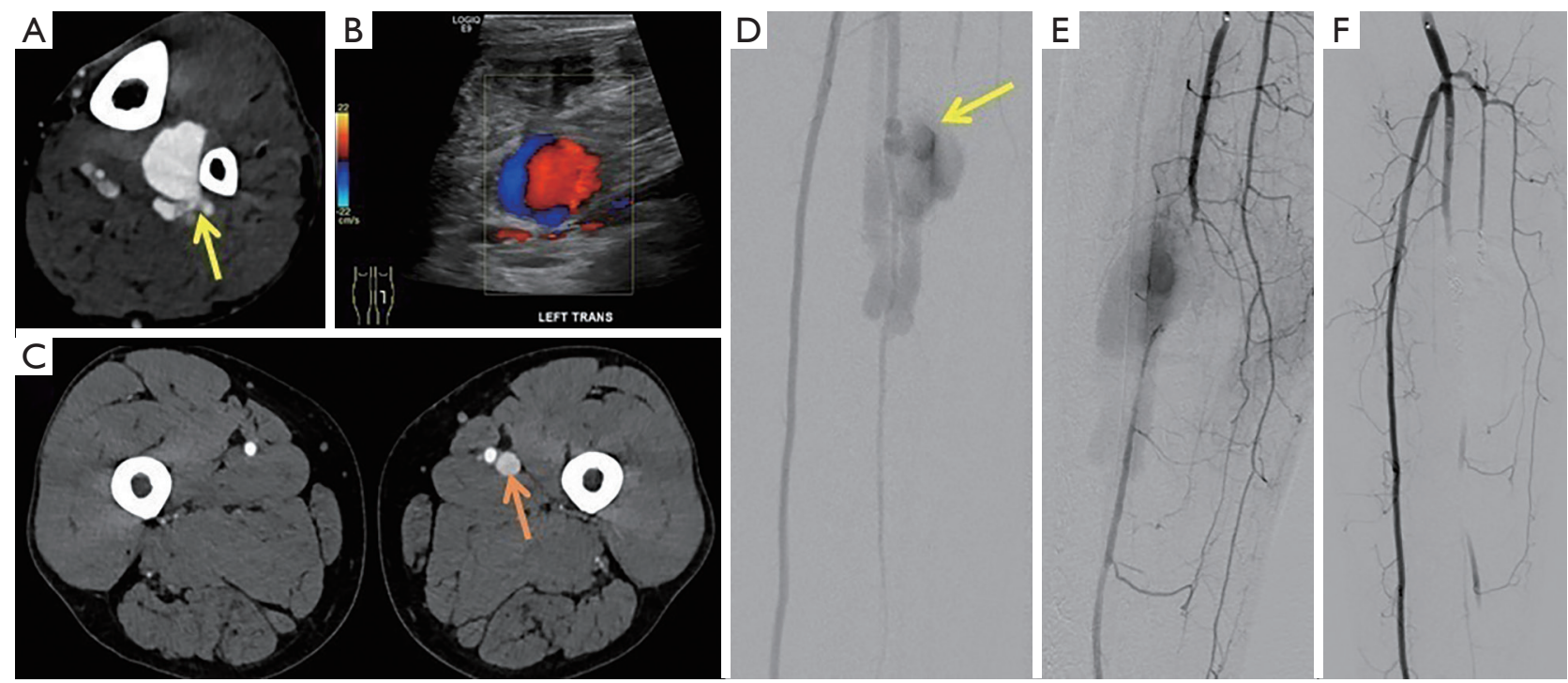

Figure 5 Coil Embolization of Traumatic Pseudoaneurysm with Arteriovenous Fistula. A 58-year-old man presented following penetrating trauma to the distal left lower extremity. (A) CT angiogram demonstrates a pseudoaneurysm directly adjacent to the peroneal artery with immediate filling of adjacent veins. (B) CT angiogram at the level of the distal thigh showing robust opacification of the femoral vein (orange arrow). Compare to the right leg where no venous filling is present. (C) Ultrasound demonstrating the characteristic "yin-yang" sign of blood flow consistent with a pseudoaneurysm. (D) Selective digital subtraction angiography (DSA) of the popliteal artery below the knee shows a pseudoaneurysm arising from peroneal artery with fistulous communication to the paired peroneal veins. (E) DSA of the anterior tibial artery demonstrates occlusion with filling of the pseudoaneurysm. Via collaterals arising from the proximal anterior tibial artery, there is reconstitution of the distal anterior tibial artery. (F) Coil embolization performed of the peroneal artery gaining both proximal and distal control. In addition, given collateral flow to the distal anterior tibial artery, the anterior tibial artery was embolized. Final images show no filling of the pseudoaneurysm with filling of the distal anterior tibial artery via collaterals.

\section{Technical challenges}

In the setting of acute extremity trauma, it is imperative to minimize blood loss as efficiently quickly as possible. Therefore, the operator should have a high level of experience with small vessel embolization (38). If hemodynamic instability were to develop while attempting an endovascular approach, balloon occlusion could be utilized to minimize blood loss while a surgical approach is considered to stabilize the patient (39).

Complex anatomy poses additional technical hurdles in the trauma setting. Rapid identification and selection of vessels that can be sacrificed safely, such as distal perforating branches of main vessels, is paramount to safe and effective embolization (38). In the event of pseudoaneurysm formation at the site of injury, it is important to stent graft or coil across the site of arterial break to prevent retrograde collateral flow into the pseudoaneurysm (40). Alternatively, the pseudoaneurysm may need to be filled with coils or other embolic agents to prevent perfusion. Pseudoaneurysms may co-exist with arteriovenous fistulas (Figure 5). Finally, in volume depleted and hemodynamically unstable patients, especially those on pressors, arteries may be constricted due to excess sympathetic tone. This can obscure underlying injuries. Additionally, it can make navigation of guidewires and catheters difficult. Finally, if one is unaware of this small vessel size, embolic or stents may be undersized leading to device migration or endoleaks.

\section{Conclusions}

Endovascular techniques are becoming increasingly utilized in all types of trauma, including arterial extremity trauma. Depending on anatomic site of injury and patient's clinical status, endovascular intervention, either by stent graft placement or embolization, can be effective with lower rates of complications and blood loss compared to open surgery. 

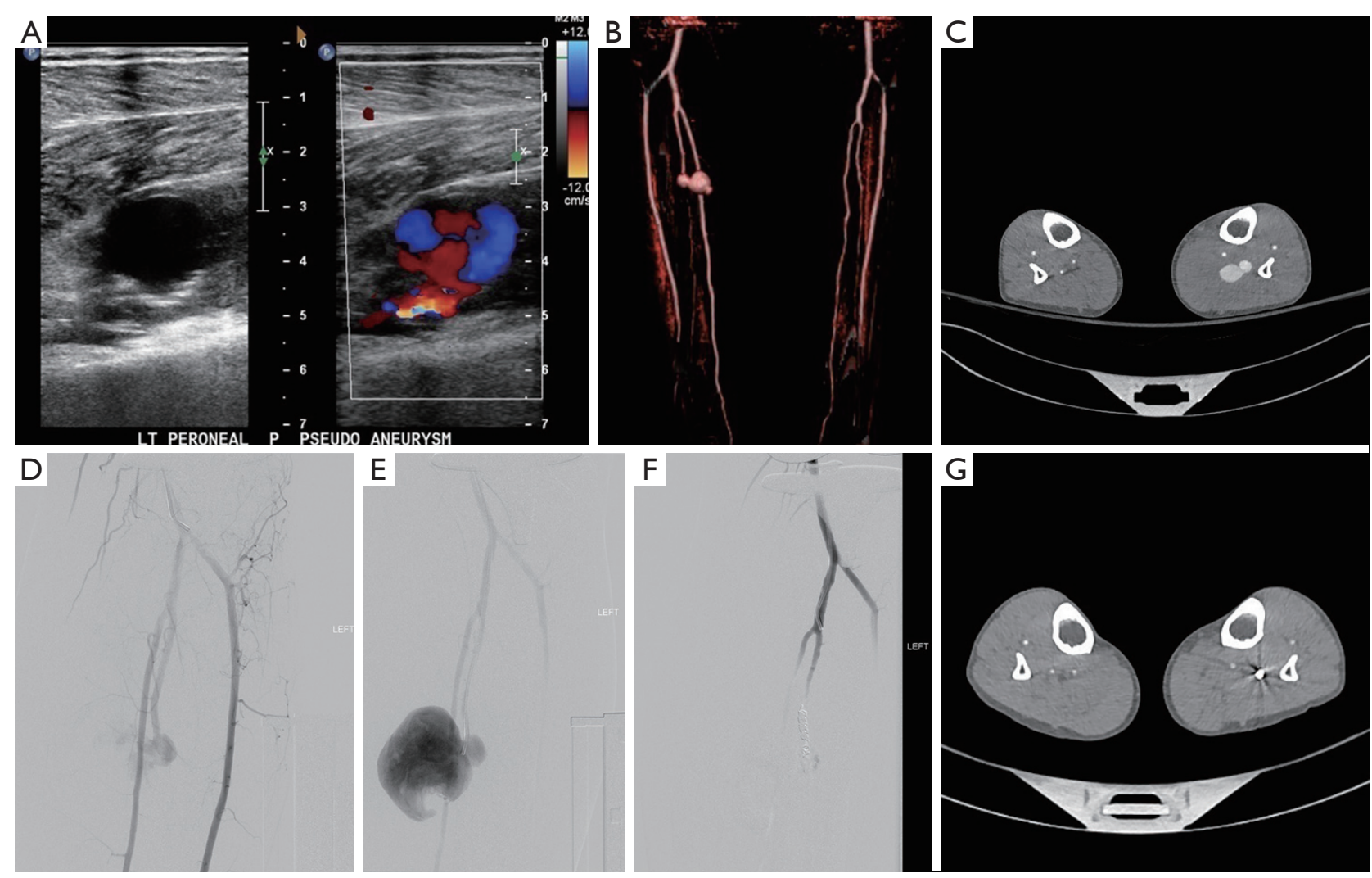

Figure 6 Peroneal artery pseudoaneurysm (PSA) treated with coil embolization. this patient was a victim of stabbing with a pulsatile hematoma in the calf. Ultrasound (US) (A) and computed tomographic angiography (CTA) (Volume Rendering-B; Axial-C) showed a large peroneal artery PSA. Angiography was performed showing the large PSA (D,E). In contrast to Figure 5, no arteriovenous fistula was seen. Successful coil embolization was performed (F). Follow-up CTA showed desired occlusion of the PSA with good maintained perfusion to the foot via the anterior and posterior tibial arteries $(\mathrm{G})$.
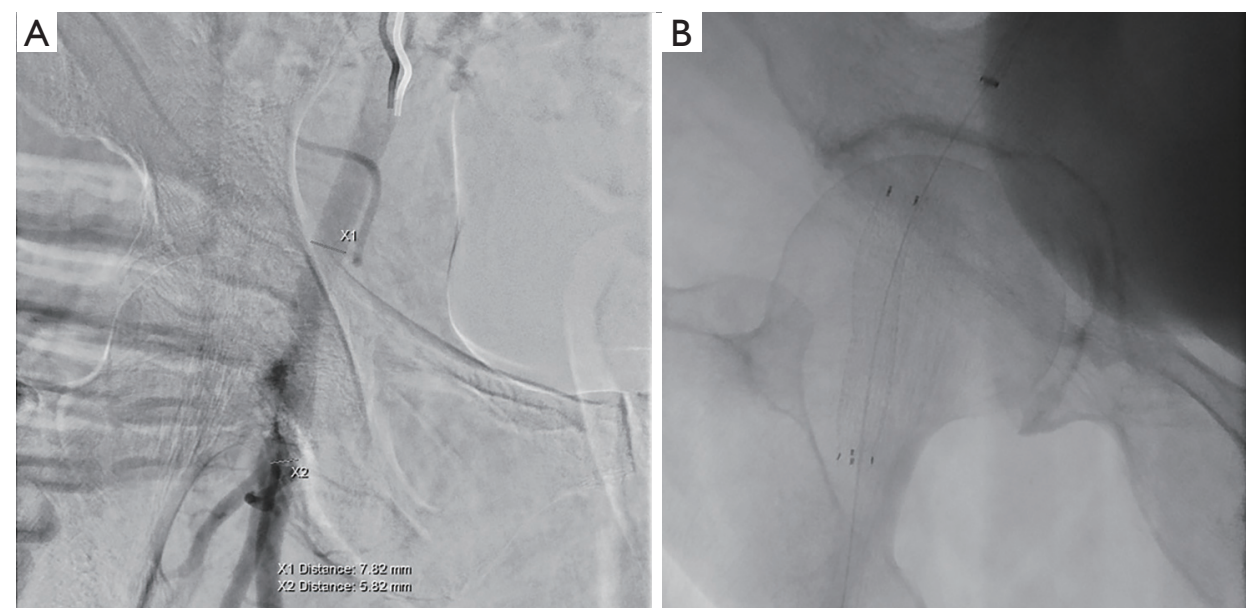

Figure 7 Stent graft placement for common femoral artery (CFA) injury. A 78-year-old female who underwent mechanical thrombectomy for middle cerebral artery (MCA) stroke. Attempted closure device placement led to significant injury to the CFA with rapidly expanding pulsatile hematoma. Contralateral access was obtained and angiography while holding pressure, showed extravasation from the CFA puncture site (A). Stent graft (Gore Viabahn W.L Gore \& Associates Flagstaff, AZ) was placed with hemostasis achieved (B). Placing stents across the hip joint should only be done in extraordinary cases given risk of stent fatigue and fracture. 


\section{Acknowledgments}

Funding: None.

\section{Footnote}

Provenance and Peer Review: This article was commissioned by the editorial office, Annals of Translational Medicine for the series "Endovascular interventions in trauma". The article has undergone external peer review.

Reporting Checklist: The authors have completed the Narrative Review reporting checklist. Available at https:// dx.doi.org/10.21037/atm-20-5428

Conflicts of Interest: All authors have completed the ICMJE uniform disclosure form (available at https://dx.doi. org/10.21037/atm-20-5428). The series "Endovascular interventions in trauma" was commissioned by the editorial office without any funding or sponsorship. KQ served as the unpaid Guest Editor of the series and serves as an unpaid editorial board member of Annals of Translational Medicine from Aug 2019 to Jul 2021. RO serves as an unpaid editorial board member of Annals of Translational Medicine from Aug 2019 to Jul 2021. The authors have no other conflicts of interest to declare.

Ethical Statement: The authors are accountable for all aspects of the work in ensuring that questions related to the accuracy or integrity of any part of the work are appropriately investigated and resolved.

Open Access Statement: This is an Open Access article distributed in accordance with the Creative Commons Attribution-NonCommercial-NoDerivs 4.0 International License (CC BY-NC-ND 4.0), which permits the noncommercial replication and distribution of the article with the strict proviso that no changes or edits are made and the original work is properly cited (including links to both the formal publication through the relevant DOI and the license). See: https://creativecommons.org/licenses/by-nc-nd/4.0/.

\section{References}

1. Papakostidis C, Kanakaris N, Dimitriou R, et al. The role of arterial embolization in controlling pelvic fracture haemorrhage: a systematic review of the literature. Eur J Radiol 2012;81:897-904.
2. Huber GH, Manna B. Vascular Extremity Trauma. In: StatPearls. Treasure Island (FL): StatPearls Publishing, 2019.

3. Mattox KL, Feliciano DV, Burch J, et al. Five thousand seven hundred sixty cardiovascular injuries in 4459 patients. Epidemiologic evolution 1958 to 1987. Ann Surg 1989;209:698-705; discussion 706-7.

4. Doody O, Given MF, Lyon SM. Extremities--indications and techniques for treatment of extremity vascular injuries. Injury 2008;39:1295-303.

5. Johnson CA. Endovascular management of peripheral vascular trauma. Semin Intervent Radiol 2010;27:38-43.

6. Jeph S, Ahmed S, Bhatt RD, et al. Novel use of interventional radiology in trauma. J Emerg Crit Care Med 2017;1:40.

7. Miller-Thomas MM, West OC, Cohen AM. Diagnosing traumatic arterial injury in the extremities with $\mathrm{CT}$ angiography: pearls and pitfalls. Radiographics 2005;25 Suppl 1:S133-42.

8. Frykberg ER. Advances in the diagnosis and treatment of extremity vascular trauma. Surg Clin North Am 1995;75:207-23.

9. Pryor JP, Braslow B, Reilly PM, et al. The evolving role of interventional radiology in trauma care. J Trauma 2005;59:102-4.

10. Johansen K, Daines M, Howey T, et al. Objective criteria accurately predict amputation following lower extremity trauma. J Trauma 1990;30:568-72; discussion 572-3.

11. deSouza IS, Benabbas R, McKee S, et al. Accuracy of Physical Examination, Ankle-Brachial Index, and Ultrasonography in the Diagnosis of Arterial Injury in Patients With Penetrating Extremity Trauma: A Systematic Review and Meta-analysis. Acad Emerg Med 2017;24:994-1017.

12. Kuwahara JT, Kord A, Ray CE Jr. Penetrating Extremity Trauma Endovascular versus Open Repair? Semin Intervent Radiol 2020;37:55-61.

13. Inaba K, Branco BC, Reddy S, et al. Prospective evaluation of multidetector computed tomography for extremity vascular trauma. J Trauma 2011;70:808-15.

14. Soto JA, Múnera F, Cardoso N, et al. Diagnostic performance of helical CT angiography in trauma to large arteries of the extremities. J Comput Assist Tomogr 1999;23:188-96.

15. Soto JA, Múnera F, Morales C, et al. Focal arterial injuries of the proximal extremities: helical CT arteriography as the initial method of diagnosis. Radiology 2001;218:188-94.

16. Jens S, Kerstens MK, Legemate DA, et al. Diagnostic 
performance of computed tomography angiography in peripheral arterial injury due to trauma: a systematic review and meta-analysis. Eur J Vasc Endovasc Surg 2013;46:329-37.

17. Wallin D, Yaghoubian A, Rosing D, et al. Computed tomographic angiography as the primary diagnostic modality in penetrating lower extremity vascular injuries: a level I trauma experience. Ann Vasc Surg 2011;25:620-3.

18. Saad NE, Saad WE, Davies MG, et al. Pseudoaneurysms and the role of minimally invasive techniques in their management. Radiographics 2005;25 Suppl 1:S173-89.

19. Franz RW, Shah KJ, Halaharvi D, et al. A 5-year review of management of lower extremity arterial injuries at an urban level I trauma center. J Vasc Surg 2011;53:1604-10.

20. McCorkell SJ, Harley JD, Morishima MS, et al. Indications for angiography in extremity trauma. AJR Am J Roentgenol 1985;145:1245-7.

21. Worni M, Scarborough JE, Gandhi M, et al. Use of endovascular therapy for peripheral arterial lesions: an analysis of the National Trauma Data Bank from 2007 to 2009. Ann Vasc Surg 2013;27:299-305.

22. Ganapathy A, Khouqeer AF, Todd SR, et al. Endovascular management for peripheral arterial trauma: The new norm? Injury 2017;48:1025-30.

23. Hutto JD, Reed AB. Endovascular repair of an acute blunt popliteal artery injury. J Vasc Surg 2007;45:188-90.

24. Zhong S, Zhang X, Chen Z, et al. Endovascular Repair of Blunt Popliteal Arterial Injuries. Korean J Radiol 2016;17:789-96.

25. Katsanos K, Sabharwal T, Carrell T, et al. Peripheral endografts for the treatment of traumatic arterial injuries. Emerg Radiol 2009;16:175-84.

26. Franz RW, Skytta CK, Shah KJ, et al. A five-year review of management of upper-extremity arterial injuries at an urban level I trauma center. Ann Vasc Surg 2012;26:655-64.

27. du Toit DF, Lambrechts AV, Stark H, et al. Long-term results of stent graft treatment of subclavian artery injuries: management of choice for stable patients? J Vasc Surg 2008;47:739-43.

28. Singh A, Kumar A, Kumar P, et al. "Beyond saving lives": Current perspectives of interventional radiology in trauma.
World J Radiol 2017;9:155-77.

29. Website [Internet]. [cited 2020 Mar 29]. Available from: https://doi.org/10.1007/s00270-003-0031-z

30. Cantasdemir M, Kantarci F, Mihmanli I, et al. Embolization of profunda femoris artery branch pseudoaneurysms with ethylene vinyl alcohol copolymer (onyx). J Vasc Interv Radiol 2002;13:725-8.

31. Lopera JE. Embolization in trauma: principles and techniques. Semin Intervent Radiol 2010;27:14-28.

32. Bauer JR, Ray CE. Transcatheter arterial embolization in the trauma patient: a review. Semin Intervent Radiol 2004;21:11-22.

33. Khurana A, Hangge PT, Albadawi H, et al. The Use of Transarterial Approaches in Peripheral Arteriovenous Malformations (AVMs). J Clin Med 2018;7:109.

34. Regine R, Palmieri F, De Siero M, et al. Embolization of traumatic and non-traumatic peripheral vascular lesions with Onyx. Interv Med Appl Sci 2015;7:22-9.

35. Biagioni RB, Burihan MC, Nasser F, et al. Endovascular treatment of penetrating arterial trauma with stent grafts. Vasa 2018;47:125-30.

36. Desai SS, DuBose JJ, Parham CS, et al. Outcomes after endovascular repair of arterial trauma. J Vasc Surg 2014;60:1309-14.

37. Neil N. Stent fracture in the superficial femoral and proximal popliteal arteries: literature summary and economic impacts. Perspect Vasc Surg Endovasc Ther 2013;25:20-7.

38. Padia SA, Ingraham CR, Moriarty JM, et al. Society of Interventional Radiology Position Statement on Endovascular Intervention for Trauma. J Vasc Interv Radiol 2020;31:363-9.e2.

39. Burdick TR, Hoffer EK, Kooy T, et al. Which Arteries Are Expendable? The Practice and Pitfalls of Embolization throughout the Body. Semin Intervent Radiol 2008;25:191-203.

40. Karkos CD, Karamanos DG, Papazoglou KO, et al. Ruptured pseudoaneurysm of the profunda femoris artery due to pellet injury: endovascular treatment by coil embolization. Cardiovasc Intervent Radiol 2009;32:837-9.
Cite this article as: Khurana A, Quencer K, Saini A, Sill A, Albadawi H, Jamal L, Naidu S, Patel I, Alzubaidi S, Oklu R. Endovascular interventions in the management of acute extremity trauma: a narrative review. Ann Transl Med 2021;9(14):1197. doi: 10.21037/atm-20-5428 